\title{
Antigenicity of amino-acid sequences from Clostridium difficile toxin B
}

\author{
J. F. TORRES* $†$ and T. P. MONATH* \\ * OraVax Inc., Cambridge, MA, USA and †Unidad de Investigacion en Enfermedades Infecciosas y Parasitarias, \\ Coordinacion de Investigacion Medica, Instituto Mexicano del Seguro Social, Mexico
}

\begin{abstract}
Clostridium difficile toxins $\mathbf{A}$ and $B$ cause antibiotic-associated colitis. Whereas antigenic determinants specifying neutralisation of toxin $A$ have been partially elucidated, those of toxin B remain unknown. To define antigenic determinants of toxin $B$, synthetic peptides were prepared for five linear sequences selected by computer analysis for putative $T$ and B epitopes. Peptides spanning the carboxy terminal region (aa 2155-2283) were also selected because this region contains repetitive units thought to bind the toxin to cell receptors. Multiple antigenic peptides were synthesised by linking four peptide copies to a core of four lysine residues (tetraMAP). Outbred mice were given four doses of each tetraMAP by intraperitoneal injection and specific immunoglobulins $G$ and $A$ were measured by enzyme-linked immunosorbent assay (ELISA) in serum, ascitic fluid and faeces. All 14 MAPs induced strong IgG responses against the homologous peptide; peptides representing aa $2155-2179$ and $2246-2270$ induced the strongest responses, of 592 and 493 ELISA units, respectively - although, to a lower extent, all 14 MAPs induced serum and faecal IgA responses against the homologous peptide. All MAPs induced IgG1 and IgG2b subclasses, documenting their capacity to elicit Th2-dependent mucosal immunity. IgG anti-MAPs were assayed for reaction with native toxins $A$ and B; most anti-MAPs recognised the toxins only weakly or did not recognise them. Antibodies against peptide representing aa 2168-2192 recognised both native toxin B (19 ELISA units) and toxin A (2 ELISA units). None of the antibodies neutralised cytotoxicity of either toxin in cell culture. In contrast, four MAPs (aa 2080-2095, 21682192, 2220-2244 and 2233-2257) inhibited cytotoxicity when mixed with toxin $B$ before addition to cells; inhibition was mediated by a direct interaction with toxin $B$.
\end{abstract}

\section{Introduction}

Clostridium difficile is an opportunist pathogen that colonises the intestine of individuals whose microbial flora has been disrupted by antibiotics or cytotoxic drugs. Toxigenic strains produce at least two toxins, A and $\mathrm{B}$; toxin $\mathrm{A}$ causes necrosis and fluid accumulation in the small and large intestine of several animal models [1-3] and is thought to be the main cause of intestinal disease in man. Damage to the intestinal mucosa might be due to direct action of the toxin on epithelial cells, as has been suggested from studies in vitro [4]; however, toxin A can also act on inflammatory cells and cause cytokine-mediated injury. It has been reported that toxin A stimulates the release of IL1 , TNF and IL- 6 by monocyte-macrophages $[5,6]$, enhances mononuclear cell cytotoxicity [7], and is

Received 25 July 1995; revised version accepted 27 Oct. 1995.

†Corresponding author: Dr J.F. Torres. chemotactic for granulocytes [8]. Anti-inflammatory drugs inhibit toxin A-associated inflammation and necrosis [9]. Toxin B causes no necrosis but induces hypersecretion in intestinal loops of rats [3] and disrupts barrier function in cultured human intestinal epithelial cells [10]. It also induces release of inflammatory mediators by human monocytes [5] and can increase cell-mediated cytotoxicity [11]. Toxin B acts synergically with toxin $A$ when given intragastrically to animals [1]. These data suggest that toxin B is also important in the pathogenesis of antibioticassociated colitis.

Because of the medical importance of $C$. difficile [12], there is interest in the development of cost-effective strategies, such as vaccines, for prevention of disease. However, the protective role of antibodies and thus of vaccines, against $C$. difficile toxins is not clear. In convalescent sera from patients who have had $C$. difficile-induced disease, a significant increase of specific IgG and IgM against toxins $A$ and $B$ has 
been reported [13]. In some studies, the presence of antibodies has correlated with reduced severity or fewer relapses $[14,15]$, but in others, a lack of correlation between immunity and clinical response has been noted [16]. Protection of hamsters against clindamycin-induced colitis was highest when animals were immunised against both toxins. Immunisation with toxin $\mathrm{A}$ alone was reported to protect from 0 to $100 \%$ of hamsters and immunisation with toxin B from 0 to $30 \%$ [17-19]. Immunisation with toxin B protected $100 \%$ of hamsters against the lethal effect of toxin B given orogastrically [18]. In ileal intestinal loops of rabbits immunised parenterally with toxin A, mucosal damage and secretion caused by toxin A was reduced significantly, whereas less protection was observed when loops were challenged with both toxin $A$ and toxin B [20].

Most vaccination studies have been performed with formalin-inactivated toxins. However, the clinical development of $C$. difficile toxoids has potential problems that include incomplete inactivation, inconsistencies in batch-to-batch properties and uncoupling from formalin. The use of subunit vaccines or synthetic peptides might overcome some of these problems. The design of synthetic vaccines involves the evaluation of selected sequences for their ability to induce humoral and mucosal immunity by providing B and $\mathrm{T}$ epitopes.

Toxins A and B are large proteins with mol. wts of 308000 and 269000 , respectively [21,22]. The toxins are similar in structure and have amino-acid sequence homology of $c$. $50 \%$. Three areas of the molecules show common structural features: a nucleotide binding region close to the $\mathrm{N}$-terminal region, a hydrophobic region of c. 170 aa in the middle of the protein, and a complex series of repeating units in the C-terminal region which comprises almost one-third of the protein [22-24]. In the case of toxin A, the Cterminal domain binds the toxin to its cell receptor, is highly immunogenic, and antibodies against it neutralise the effect of the toxin in the intestine $[25,26]$. The domain for binding of toxin $B$ is unknown; however, by analogy with toxin $\mathrm{A}$, the C-terminal repeat region is thought to represent the binding domain. Although this region may contain determinants for neutralising $(\mathrm{N})$ antibodies, no $\mathrm{N}$ sites have yet been specifically identified and no $\mathrm{N}$ monoclonal antibodies have been developed.

The purpose of this study was to evaluate the antigenicity of peptides comprising linear amino-acid sequences from toxin B synthesised as multiple antigenic peptides, a technique that avoids the drawbacks of using a carrier protein [27]. Peptides containing putative $\mathrm{B}$ and $\mathrm{T}$ epitopes or comprising repetitive sequences in the $\mathrm{C}$-terminal region of the protein were evaluated in rodents for their ability to induce serum IgG and IgA antibodies as well as secretory IgA antibodies. The ability of the antibodies to recognise the native holotoxin as well as to neutralise its cytotoxicity was evaluated.

\section{Materials and methods}

\section{Peptides}

Table 1 shows the toxin $B$ aa sequences synthesised as multiple antigenic peptides (MAPs) by covalently linking four peptides (tetraMAPs) to a core of four lysines as previously described $[27,28]$. Fig. 1 shows the localisation of these sequences in the toxin protein. MAPs were synthesised by Dr Charles Dahl (Department of Biological Chemistry and Molecular Pharmacology Harvard Medical School, Boston, USA). Five linear sequences containing putative $\mathrm{T}$ and $\mathrm{B}$ epitopes were selected. $\mathrm{T}$ epitopes were amphipathic regions containing an $\alpha$-helix or a sequence with a G followed by two or three hydrophobic residues and a charged or polar residue. B epitopes were sequences with high hydrophilicity, protrusion index, mobility and the presence of a $\beta$-turn. Sequences with these characteristics were identified by the PLOTSTRUCTURE software program and designated as MAPs 1, 2, 3, 4 and 5. Nine peptides spanning the carboxy-terminal region 2155-2283 were chosen because this region of the

Table 1. Amino-acid sequences from toxin B synthesised as tetraMAPs

\begin{tabular}{lll}
\hline MAP no. & aa region & \multicolumn{1}{c}{ Sequence } \\
\hline 1 & $1892-1906$ & GVLQTGVFSTEDGFK \\
2 & $1927-1947$ & GKLI-IDENIYYFDDNYRGAVE \\
3 & $1985-2003$ & MQKGFVSINDNKHYFDDSG \\
4 & $2080-2095$ & KDLEDGSKYYFDEDTA \\
5 & $2134-2150$ & SGIIESGVQNIDDNYFY \\
6 & $2155-2179$ & GIVQIGVFDTSDGYKYFAPANTVND \\
7 & $2168-2192$ & YKYFAPANTVNDNIYGQAVEYSGLV \\
8 & $2181-2205$ & IYGQAVEYSGLVRVGEDVYYFGETY \\
9 & $2194-2218$ & VGEDVYYFGETYTIETGWIYDMENE \\
10 & $2207-2231$ & IETGWIYDMENESDKYYFNPETKKA \\
11 & $2220-2244$ & DKYYFNPETKKACKGINLIDDIKYY \\
12 & $2233-2257$ & KGINLIDDIKYYFDEKGIMRTGLIS \\
13 & $2246-2270$ & DEKGIMRTGLISFENNNYYFNENGE \\
14 & $2259-2283$ & ENNNYYFNENGEMQFGYINIEDKMF \\
\hline
\end{tabular}



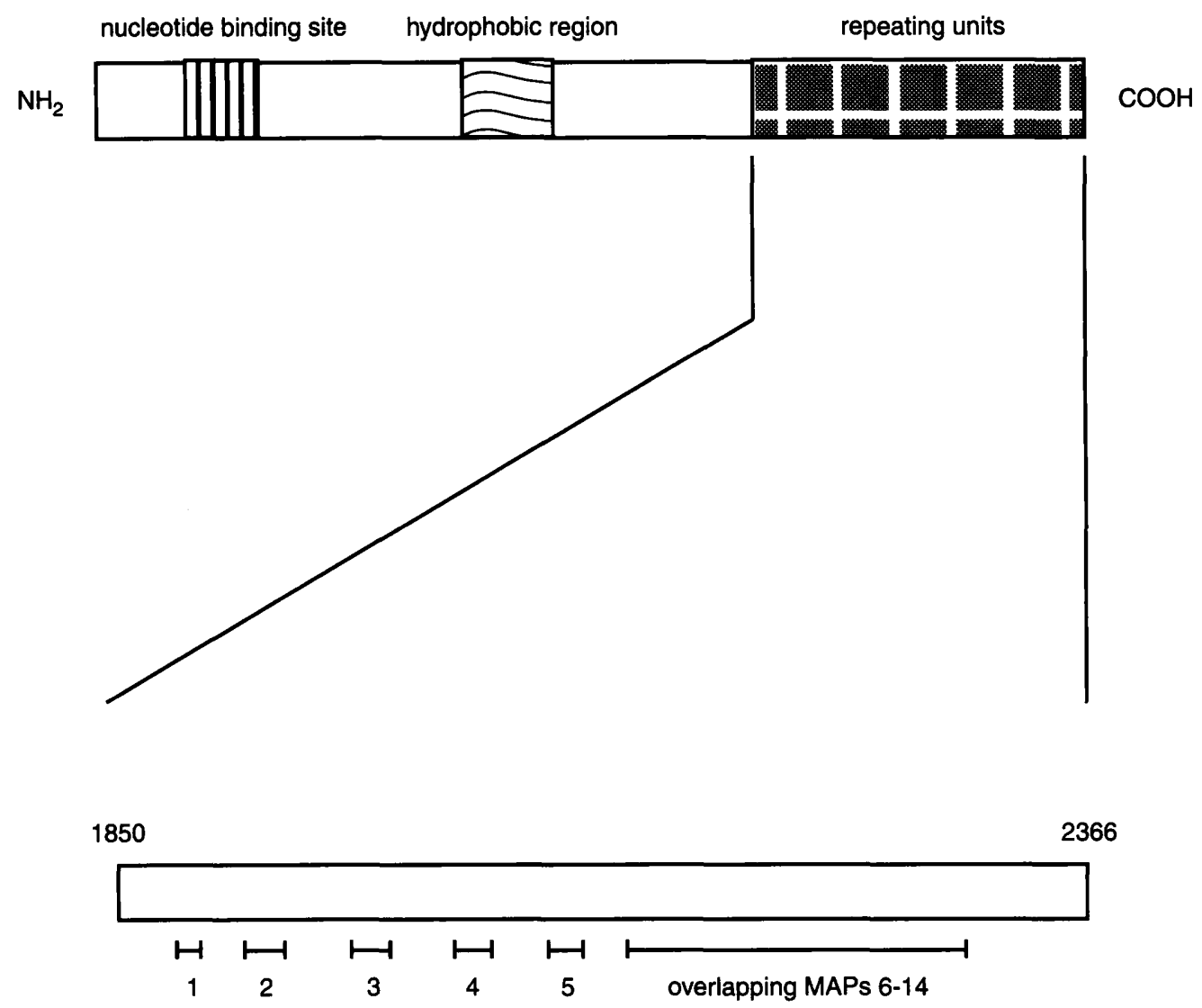

Fig. 1. Localisation of the amino-acid sequences chosen for synthesis in the toxin B protein. Structure depicted is based on published data $[23,24]$.

toxin contains repetitive aa sequences suspected to be involved in binding to receptor. These peptides were overlapping 25-mers designated as MAPs 6-14. MAPs $1,3,4,10,11$ and 12 were soluble in water, whereas peptides $2,5,6,7,8,9,13$ and 14 were solubilised in dimethylsulphoxide $10 \%$.

\section{Animals}

Female Swiss Webster mice 8-10 weeks old (Taconic, Germantown, NY, USA) were used for immunisation. Groups of five animals were given $50 \mu \mathrm{g}$ of each tetraMAP by intraperitoneal (i.p.) injection at days 0 and 7 and $10 \mu \mathrm{g}$ of each tetraMAP, plus $0.1 \mathrm{ml}$ RIBI adjuvant (RIBI ImmunoChem, Hamilton, MT, USA) at days 14 and 28. A group of five animals was given RIBI and no MAP by i.p. injection at days $0,7,14$ and 28 as a negative control. Immune ascitic fluid was induced by injecting $10^{5}$ sarcoma cells (180/TG) i.p. on day 38; and ascitic fluid, blood, and faeces were collected on day 48. Blood and ascitic fluid were allowed to clot overnight at $4^{\circ} \mathrm{C}$, centrifuged and the supernate was frozen at $-80^{\circ} \mathrm{C}$. Faecal specimens for antibody determinations were prepared as follows. Five faecal pellets were mixed thoroughly in $1 \mathrm{ml}$ of phosphate-buffered saline (PBS) $\mathrm{pH}$ 7.4, containing protease inhibitors, $0.2 \mathrm{mM}$ aminoethyl-benzene sulphonyl fluoride (Calbiochem, La Jolla, CA, USA), aportinin (Sigma) $1 \mu \mathrm{g} / \mathrm{ml}, 10 \mu \mathrm{M}$ leupeptin (Sigma) and $3.25 \mu \mathrm{M}$ bestatin (Sigma), and non-fat dry milk $5 \%$; after centrifugation, supernates were frozen at $-80^{\circ} \mathrm{C}$.

\section{Quantification of immunoglobulins}

All reagents were obtained from Southern Biotech, Birmingham AL, USA, unless otherwise specified. Total content of IgG was estimated in blood and ascitic fluid. Microtitration plates (Corning, New York, NY, USA) were coated $(1 \mu \mathrm{g} /$ well) with unlabelled goat anti-mouse IgG (heavy chain specific, absorbed with mouse IgM and IgA) in carbonate-bicarbonate buffer (CBB) $\mathrm{pH} 9.3$, overnight at $4^{\circ} \mathrm{C}$; plates were then washed and blocked with non-fat dry milk $2.5 \%$ in PBS (PBSM). Test samples were then added at twofold dilutions from 1 in 10000 to 1 in 640000 in PBSM and incubated for $1 \mathrm{~h}$ at $37^{\circ} \mathrm{C}$. An isotype control was added to each plate, consisting of purified mouse IgG from 0.8 to $50 \mathrm{ng} / \mathrm{ml}$. Plates were washed and biotinylated goat anti-mouse IgG (heavy chain specific) diluted 1 in 1000 was added and incubated for $1 \mathrm{~h}$ at $37^{\circ} \mathrm{C}$. After washing, streptavidin-alkaline phosphatase diluted 1 in 500 was added, the plates were incubated for $1 \mathrm{~h}$ at $37^{\circ} \mathrm{C}$, and then washed before addition of substrate ( $p$-nitrophenyl phosphate). Optical density (OD) was read at $405 \mathrm{~nm}$ and the concentration of IgG in each sample was determined by comparing values with the isotype standard curve prepared in each 
plate and analysed with Softmax software (Molecular Devices, Sunnyvale, CA, USA). To estimate the content of specific IgG against the homologous peptide, plates were coated $(1 \mu \mathrm{g} /$ well $)$ with the tetraMAP used as immunogen in CBB overnight. The plates were then blocked with PBSM and treated with serum or ascitic fluid diluted from 1 in 5000 to 1 in 320000 . As for total IgG, a standard curve was used in each plate, and wells were coated with purified mouse IgG to estimate the concentration of specific IgG in the samples. The IgG value against each MAP obtained with serum or ascitic fluid from RIBI immunised animals (negative control) was subtracted from the value obtained with serum or ascitic fluid specific IgG for each anti-MAP. Due to possible differences in the affinity of standard isotype mouse IgG for the ELISA plates and affinity of specific IgG antibodies for the MAPs, results are not reported as ng of specific $\mathrm{IgG} / \mu \mathrm{g}$ of total IgG; instead the values were normalised for the total content of IgG and expressed as ELISA units. One ELISA unit was defined as $1 \mathrm{ng}$ of specific $\mathrm{IgG} / \mu \mathrm{g}$ of total IgG. The presence of subclasses IgG1, IgG2a, IgG2b and IgG3 in each anti-MAP was estimated similarly, except that the second antibody was the respective biotin-conjugated goat anti-mouse IgG subclass ( $\gamma$ subclass chain specific) and the standard curve in each plate was created by coating wells with the corresponding purified mouse IgG subclass. One ELISA unit was equivalent to $1 \mathrm{ng}$ of specific IgG subclass/ $\mu \mathrm{g}$ of total IgG. IgG subclass ELISA units for each anti-MAP were summed up and the percentage for each IgG subclass was calculated.

Total IgA content was estimated in blood, ascitic fluid and faeces; plates were coated $(1 \mu \mathrm{g} /$ well $)$ with unlabelled goat anti-mouse $\operatorname{IgA}(\alpha$ chain specific) and processed as above. Blood and ascitic fluid were added in two-fold dilutions from 1 in 1000 to 1 in 64000. Purified mouse IgA (Zymed, San Francisco, CA, USA) in two-fold dilutions, from 100 to $1.6 \mathrm{ng}$ / $\mathrm{ml}$ was added as isotype standard in each plate. Biotinylated goat anti-mouse IgA ( $\alpha$ chain specific), streptavidin-alkaline phosphatase and substrate were used as above. Specific IgA was measured by coating the plates $(1 \mu \mathrm{g} /$ well) with the homologous tetraMAP, and treating with serum or ascitic fluid at dilutions from 1 in 10 to 1 in 640 and with faeces at 1 in 5 to 1 in 320 . The IgA values against each MAP obtained with serum, ascitic fluid or faeces from RIBI immunised animals (negative control), were subtracted from the values obtained with serum, ascitic fluid or faeces specific IgA for each anti-MAP. Values were then normalised for total content of IgA and expressed as ELISA units. One ELISA unit was defined as $1 \mathrm{ng}$ of specific $\operatorname{IgA} / \mu \mathrm{g}$ of total $\operatorname{Ig} \mathrm{A}$.

\section{ELISA for reaction of anti-MAPs with toxins}

To study the recognition and specificity of native toxins with antibodies raised to the 14 MAPs, each well was coated with $2 \mu \mathrm{g}$ of toxin B or $4 \mu \mathrm{g}$ of toxin A purified as described previously [26] (LabTech, Blacksburg, VA, USA), and ELISA was performed as described above with serially diluted ascitic fluid. Specific IgG $(\mathrm{ng} / \mathrm{ml})$ was estimated by analysing the absorbance of the samples in a curve prepared by coating wells with purified mouse IgG in each plate. The IgG value obtained against each toxin with ascitic fluid from RIBI immunised animals (negative control) was subtracted from the values obtained with ascitic fluid specific IgG antibodies for each anti-MAP. Values were then normalised for the total content of $\operatorname{IgG}$ and expressed as ELISA units (ng of specific IgG $/ \mu \mathrm{g}$ of total IgG).

\section{Reaction of anti-MAPs with denatured toxins}

Preparative SDS-PAGE $12 \%$ gels were loaded with either $38 \mu \mathrm{g}$ of toxin B or $93 \mu \mathrm{g}$ of toxin $\mathrm{A}$ and run under reducing conditions at $200 \mathrm{~V}$ for $1.2 \mathrm{~h}$. Proteins were transfered to nitrocellulose membranes. Membranes were then blocked with PBSM, mounted in a multiscreen apparatus (BioRad, Hercules, CA, USA) and anti-MAPs were added at a final dilution of 1 in 300; ascitic fluid from RIBI immunised mice was also tested at a 1 in 300 dilution. After washing, goat antimouse IgG alkaline-phosphatase conjugate was added and the reaction product visualised by adding NBT/ BCIP substrate (Gibco, Gaithersburg, MD, USA). Positive controls included a monoclonal antibody (PCG-4) against toxin $\mathrm{A}$ and a polyclonal goat antitoxin B (both gifts of Dr D. Lyerly LabTech, Blacksburg, VA, USA).

\section{Inhibition of cytotoxicity}

To determine the ability of the 14 anti-MAPs to neutralise the cytotoxicity of toxin B, ascitic fluid was diluted 1 in 10 in PBS and then mixed with an equal volume of toxin $B$ in two-fold dilutions from 10 to $0.07 \mathrm{ng} / \mathrm{ml}$. A curve in each plate with only toxin B was used to define the minimal dose producing a cytopathic effect in $100 \%$ of the cells (1 TCD100). Ascites from RIBI immunised animals were included as negative control and the polyclonal goat anti-toxin B was used as a positive control for neutralisation. The antibody-toxin mixture was incubated for $1 \mathrm{~h}$ at $37^{\circ} \mathrm{C}$ and $20 \mu \mathrm{l}$ were added to Chinese hamster ovary (CHO) cells in duplicate 96-well microtitration plates. Cytopathic effects were recorded $20 \mathrm{~h}$ later to determine the number of TCD100 inhibited by the sample [29].

All 14 MAPs were also tested for their capacity to block toxin B cytotoxicity: $10 \mu \mathrm{g}$ of each MAP were added to duplicate wells containing confluent $\mathrm{CHO}$ cells, incubated for 10 min and toxin B was added in two-fold dilutions as above. After $20 \mathrm{~h}$, the number of TCD100 inhibited was recorded. 


\section{ELISA for reaction of MAPs with toxin $B$}

To study the recognition of toxin B by MAPs, plates were coated with toxin B $2 \mu \mathrm{g} /$ well and blocked with PBSM as described above. MAPs 4, 7, 11 and 12 were added in two-fold dilutions from 100 to $3.1 \mu \mathrm{g} / \mathrm{ml}$ and incubated for $1 \mathrm{~h}$ at $37^{\circ} \mathrm{C}$. Next, the homologous antiMAP ascitic fluids were added in a 1 in 1000 dilution and incubated for $1 \mathrm{~h}, 37^{\circ} \mathrm{C}$; this dilution was chosen because it gave a strong reaction with the MAP and a very weak reaction with toxin $B$. Some of the wells coated with toxin B were treated directly with antiMAPs at a dilution of 1 in 1000. Biotinylated goat antimouse IgG was added and the reaction was visualised as described earlier. For each toxin-MAP reaction, the absorbance obtained from the reaction between toxin $\mathrm{B}$ and anti-MAP was subtracted from the absorbance obtained when the reaction mixture contained toxin B and both MAP and anti-MAP.

\section{Results}

Humoral immune response against homologous MAPs

IgG and IgA antibody responses in sera of individual mice immunised with each MAP were first evaluated and compared with the response in pooled ascitic fluid. As ELISA endpoint titres in ascitic fluid were highly correlated with the mean serum response of each group of five mice (data not shown), only values in ascitic fluid are presented. The specific IgG responses in ascitic fluid ranged from $c$. 100 to 600 ELISA units, as shown in Figure 2. MAPs 6, 11, 12, 13 and 14 induced the strongest antibody responses with $>400$ ELISA units. In ascitic fluid, the concentrations of specific IgA reactive with the homologous peptide were considerably lower than for IgG, with c. 0.2 ELISA units for most MAPs. Exceptions were MAPs 3 and 10 that induced IgA responses $>0.4$, and MAP 13 that induced
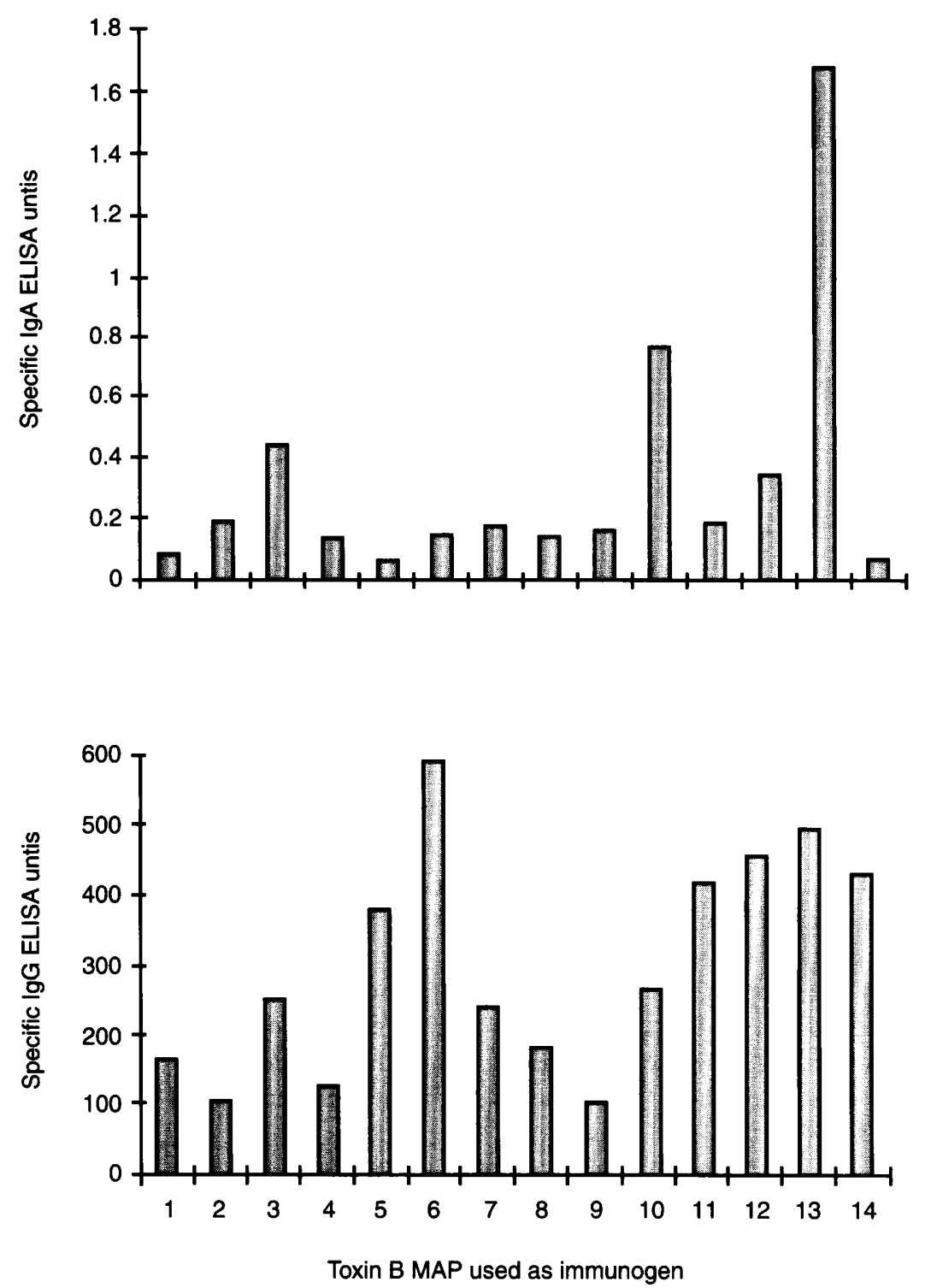

Fig. 2 Estimation of concentration of specific IgG and IgA in ascitic fluid from mice immunised with toxin B tetraMAPs; specific Ig ( $\mathrm{ng} / \mathrm{mg}$ ) is against the tetraMAP used as immunogen (homologous peptide). Each bar is the result obtained with ascitic fluid pooled from the five animals in each group and is the mean of at least two assays. 
1.67 ELISA units. Faecal IgA was also evaluated (Fig. 3). Considerable individual variation was found between animals immunised with each MAP. However, IgA responses generally reflected values observed in ascitic fluid IgA; MAPs 3, 10, 12 and 13 induced the strongest faecal IgA responses.

The ability of these MAPs to activate Th1 and Th2 was tested indirectly by measuring the content of specific IgG subclasses in ascitic fluid (Fig. 4). The responses induced by MAPs $1,4,5$ and 10 were characterised by antibodies of the IgG1 subclass. MAP 6 elicited antibodies with a strong response in the IgG2b subclass, and MAPs 13 and 14 elicited a dominant IgG2a response. IgG3 subclass antibodies were rare with all MAPs.

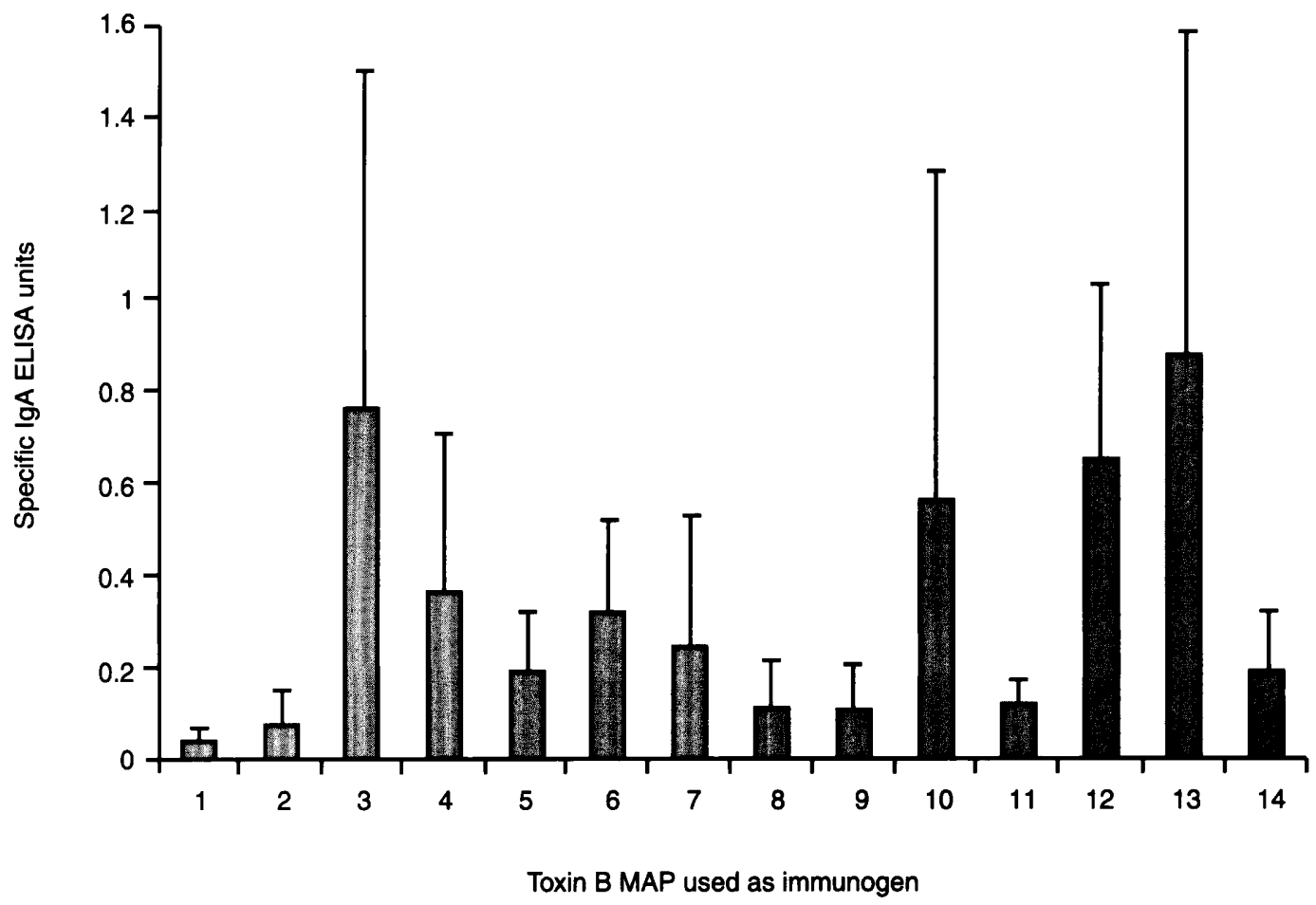

Fig. 3. Content of specific IgA (ng/mg of total IgA) against the tetraMAP used as immunogen in faeces from mice immunised with toxin B tetraMAPs. Each bar represents the mean and SE of the five mice/group tested individually; assays were done in duplicate.

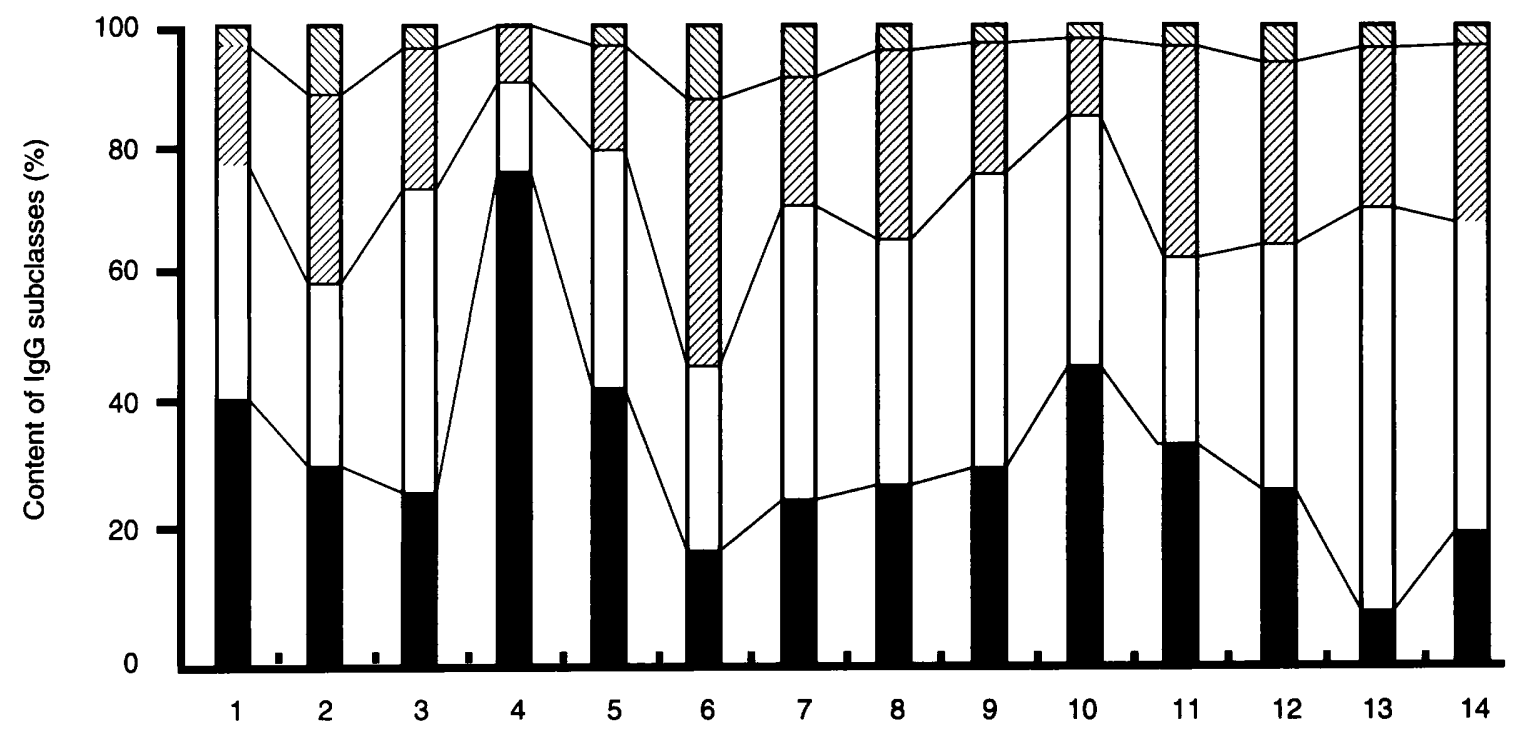

Toxin B MAP used as immunogen

Fig. 4. IgG subclass antibodies in mice immunised with toxin B peptides. The content of IgG subclasses reactive with the tetraMAP used as immunogen, as measured by ELISA, is expressed as a percentage of the total content of specific IgG: $\mathbb{Q}, \operatorname{IgG} 3 ; \mathbb{Z}$, IgG2b; $\square$, IgG2a; $\mathbf{D}, \operatorname{IgG} 1$. 


\section{Recognition of toxins $A$ and $B$}

Ascitic fluid IgG raised to some MAPs recognised native toxin $B$ and showed cross-reactivities with toxin A (Fig. 5). Anti-MAP 7 has the strongest reaction with toxin B. Anti-MAP 6, which also reacted with native toxin $B$, was raised against a peptide that overlapped MAP 7. Anti-MAPs 2, 3, 4 and 14 also showed moderate reactivity with toxin B. Anti-MAPs 5, 8, 9, 10,12 and 13 gave weak reactions, and anti-MAPs 1 and 11 did not recognise the toxin. Native toxin A was recognised by anti-MAPs $3,6,7$ and 11 . Western blots showed recognition of denatured toxin $B$ by most antisera, except for anti-MAPs 1, 5 and 10 (Fig. 6a). Anti-MAPs 3, 6, 7 and 10 showed reactivity with denatured toxin A (Fig. 6b). Anti-MAPs 4 and 14 reacted with denatured toxin $B$ but not with denatured toxin A. Ascitic fluid from RIBI immunised mice showed no reactivity with either toxin. Sequences from all MAPs studied are included in the C-terminal portion of toxin B. The homologies of the toxin $B$ MAPs sequences $3,6,7$ and 10 with toxin $A$ are shown in Table 2. MAP 3 has $37 \%$ homology ( $68 \%$ similarity) with toxin A repeat $\mathrm{IID}_{2}$. MAPs 6 and 7 have 60 and $52 \%$ homology, respectively, with toxin A repeat class $\mathrm{I}_{5}$; both MAPs have the sequence YFAPANT which is conserved in all seven class I repeats of toxin A. MAP 10 has $36 \%$ homology with toxin $A$ repeat IIB $_{10}$; and the sequence KYYFN is conserved in 10 of the 13 class IIB repeats of toxin A. MAPs 4 and 14, which did not show cross reactivity with toxin A, had homologies of 25 and $32 \%$, respectively, with toxin A (Table 2).

\section{Inhibition of toxin $B$ cytotoxicity}

None of the anti-MAPs inhibited toxin B-induced cytotoxicity in $\mathrm{CHO}$ cells. To determine whether the
MAPs might compete with toxin B for binding to cells, $10 \mu \mathrm{g}$ of each MAP were added to cells for $10 \mathrm{~min}$ before challenge with toxin B. MAPs 4 and 7 inhibited one TCD100, MAP 12 inhibited 2 TDC100; whereas MAP 11 was able to inhibit $16 \mathrm{TDC} 100$. The inhibitory activity of MAP 11 was further characterised. MAP 11 at concentrations of $2,4,8$ and $16 \mu \mathrm{g} /$ well was tested to determine the minimal dose required to inhibit 2 TCD100. A minimum of $8 \mu \mathrm{g}$ was required to inhibit cytotoxicity. MAP 11 at $8 \mu \mathrm{g} /$ well was then added -60 , $-30,-15,0,+15$ and $+30 \mathrm{~min}$ in relation to the time of toxin B challenge with 2 TCD100 (Fig. 7). When MAP was added to cells before addition of toxin, no inhibition was observed; however, when both MAP and toxin were added together or when MAP was added shortly after toxin B, cytotoxicity was inhibited. These results suggest that some MAPs might interact with toxin B and not with cell receptors; this possibility was studied by ELISA (Fig. 8). MAPs 11 and 12 were shown to react with toxin B at concentrations $<10 \mu \mathrm{g} /$ $\mathrm{ml}(\mathrm{OD}>0.5)$, whereas only high concentrations of MAPs 4 and 7 recognised toxin $B$.

\section{Discussion}

As $C$. difficile colitis is a toxin-mediated disease, strategies for prevention should focus on immunity against toxins; in fact, clinical and experimental reports suggest that antitoxin immunity may prevent disease $[14,15,17-19]$. Toxin $\mathrm{A}$ is a highly immunogenic protein and its repetitive sequences in the C-terminal region induce antibodies that protect against enterotoxicity in experimental animals [26]. Toxin B is less efficient as an immunogen and no immunodominant or protective epitopes have been described. In an attempt to define antigenic determinants in toxin $\mathrm{B}$, linear

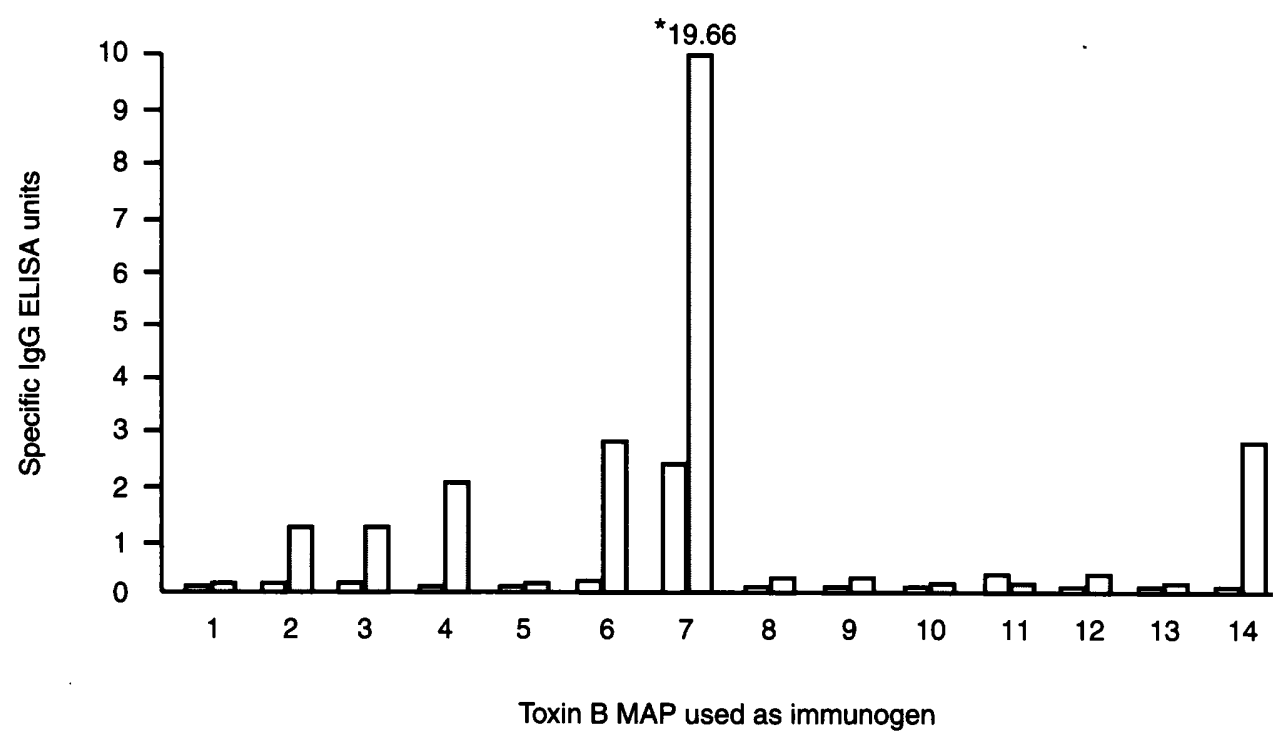

Fig. 5. Recognition of native toxin A and toxin B by IgG antibodies against toxin B tetraMAPs in ascitic fluids from mice immunised with toxin B peptides in ELISA with purified toxin A ( $\square$ ) or toxin B ( $\square$ ) attached to microtitration plates. Bars represent the mean of two assays; ${ }^{*}$, indicates the value of anti-MAP 7 with toxin B. 
a

$\begin{array}{llllllllllllll}1 & 2 & 3 & 4 & 5 & 6 & 7 & 8 & 9 & 10 & 11 & 12 & 13 & 14\end{array} \mathrm{kDa}$

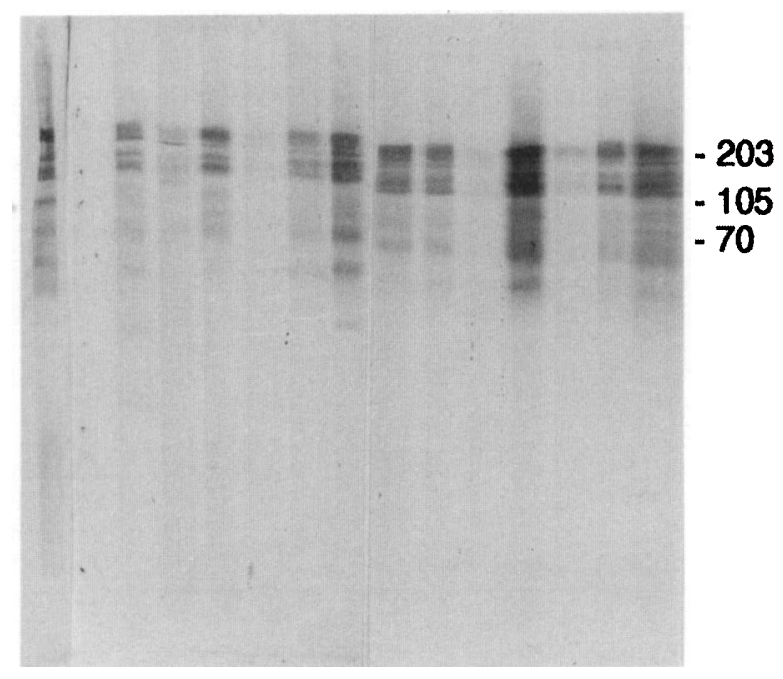

b

$\begin{array}{lllllllllllllll}C & 2 & 3 & 4 & 5 & 6 & 7 & 8 & 9 & 10 & 11 & 12 & 13 & 14 \quad \mathrm{kDa}\end{array}$

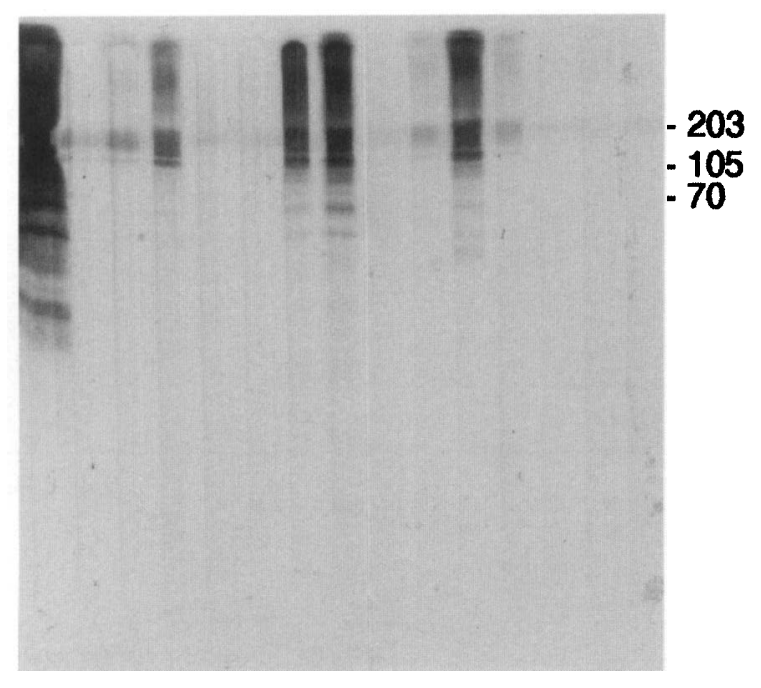

Fig. 6. Recognition of denatured toxins $A$ and B by antibodies against toxin B tetraMAPs. Toxins separated by SDSPAGE and transferred to nitrocellulose were exposed to ascitic fluids from mice immunised with toxin B peptides, followed by anti-mouse IgG-AP. a, Gel run with toxin B, row C goat polyclonal anti-toxin B (revealed with anti-goat IgG); b gel run with toxin A, row C monoclonal PCG-4. In both gels, rows 1-14 are anti-MAPs 1-14 respectively; mol. wt markers are indicated on the right.

sequences of toxin B were mapped by the systemic and mucosal antibody responses induced by synthetic peptides after intraperitoneal immunisation of mice.

One of the purposes of this work was to identify sequences with $\mathrm{T}$ epitopes and, therefore, peptides were not conjugated to a carrier protein, but were synthesised as multivalent tetraMAPs; such antigens are high density immunogens and avoid undesirable immune responses to the protein carrier by the host [27]. By this method, most of the linear sequences tested were able to induce strong $\operatorname{IgG}$ and $\operatorname{IgA}$ reponses against the homologous peptide, indicating the stimulation of Th cells, and adding to the evidence that MAPs efficiently induce humoral immune responses $[28,30]$. The fact that an immune response was raised with most of these peptides indicates that $\mathrm{B}$ cell epitopes are also present.

Peptides encompassing the aa sequences 1985-2003 (MAP 3), 2207-2231 (MAP 10) and 2246-2270 (MAP 13) were efficient inducers of $\operatorname{IgA}$ in both 
Table 2. Amino-acid sequence homology between toxin B MAPs 3, 4, 6, 7, 10 and 14 with toxin $A$

\begin{tabular}{|c|c|c|}
\hline MAP & Amino acid region & Sequence and homology* \\
\hline 3 & $\begin{array}{l}\text { Toxin B 1985-2003 } \\
\text { Toxin A 1984-2003 }\left(\mathrm{IID}_{2}\right)^{\dagger}\end{array}$ & $\begin{array}{l}\text { MQKGFVSINDNKHYFD-DSG } \\
\# \star \star \# \# \star \# \star \star \star \star \star \# \\
\text { ISKGWOTVNGSRYYFDTDTA }\end{array}$ \\
\hline 4 & Toxin B $2080-2095$ & $\begin{array}{l}\text { KDLEDGSKYYFDEDTA } \\
\# \# \quad \star \star \star \star\end{array}$ \\
\hline & Toxin A 1984-2003 $\left(\mathrm{IID}_{2}\right)^{\dagger}$ & RIIN-NKKYYFNPNNA \\
\hline 6 & Toxin B $2155-2179$ & $\begin{array}{l}\text { GIVQIGVFDTSDGYKYFAPANTVMD } \\
\star \star \star \# \star \star \star \star \star \star ~\end{array}$ \\
\hline & Toxin A $2405-2429\left(I_{5}\right)$ & GIMQIGVFKGPNGFEYFAPANTDAN \\
\hline 7 & $\begin{array}{l}\text { Toxin B } 2168-2192 \\
\text { Toxin A } 2417-2442\left(I_{5}\right)\end{array}$ & 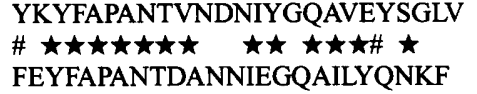 \\
\hline 10 & Toxin B $2207-2231$ & $\begin{array}{l}\text { IETGWIYDMENESDKYYFNPETKKA } \\
\star \star \star\end{array}$ \\
\hline & Toxin A 2458-2479 (IIB $\left.{ }_{10}\right)$ & AVTGLR---TIDGKKYYFNTNTAVA \\
\hline 14 & $\begin{array}{l}\text { Toxin B } 2259-2283 \\
\text { Toxin A } 2508-2532\left(\mathrm{IIC}_{5} \text { and } \mathrm{I}_{6}\right)\end{array}$ & 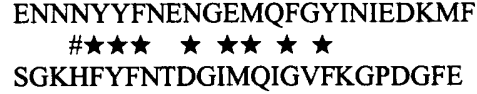 \\
\hline
\end{tabular}

${ }^{*} \#$, Denotes similarity; $\star$, denotes identity; -, denotes theoretical deletions.

${ }^{\dagger}$ Repeats of toxin A based on reference 22 .

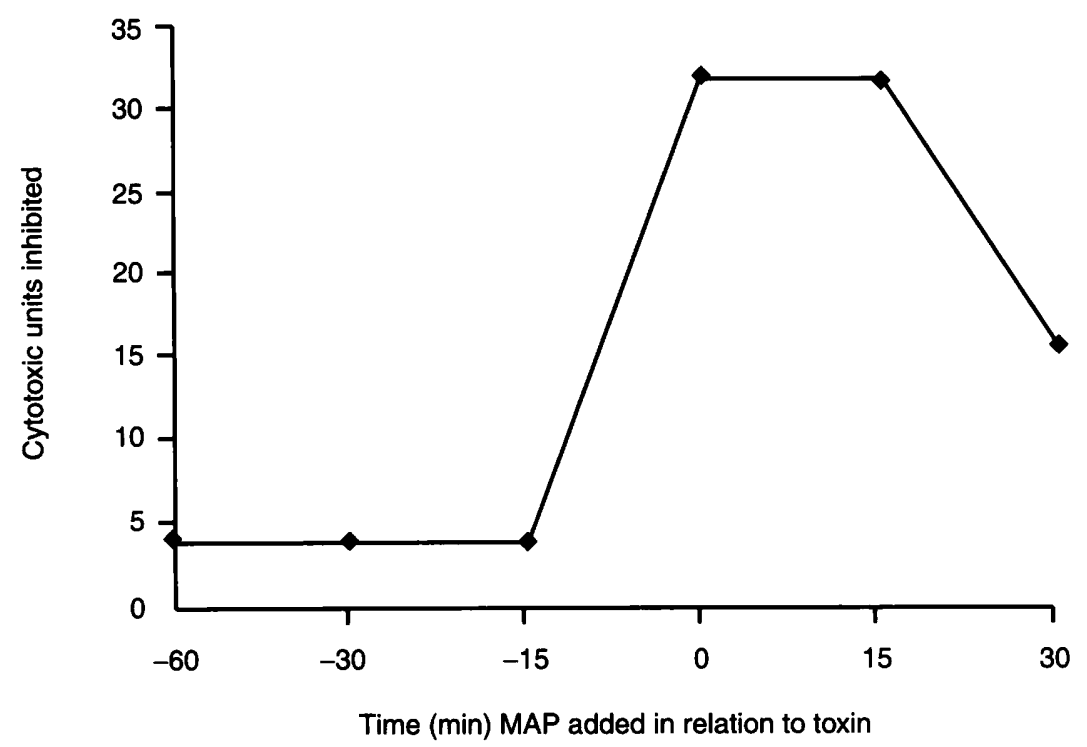

Fig. 7. Inhibition of toxin B cytotoxicity for CHO cells by tetraMAP 11 added to cells at different times in relation to the addition of toxin $B$. Values are the mean of three assays.

blood and mucosal compartments. These regions of the toxin might represent suitable candidates as part of a subunit vaccine aimed at raising mucosal immunity. The ability of some of these sequences to elicit secretory IgA was supported by the pattern of IgG subclasses produced, since high levels of IgG1 and IgG2b were observed, those subclasses known to be induced by activated Th2 helper cells [31,32]. However, MAPs 1,4 and 5 induced high levels of IgG1 but only low levels of IgA; this discrepancy is unexplained.

The high antigenicity of these linear sequences is in contrast with the poor immune response observed when purified toxin $B$ is used as the antigen [19]. The toxin is known to interact with immune cells and alter some of its functions. Low concentrations of toxin B activate human monocytes to release pro-inflammatory monokines [5], and can also be toxic to antigenpresenting cells $[5,33]$. Thus, it is possible that even after inactivation, the uptake and processing of the toxin by immune cells do not favour stimulation of $B$ and $T$ cells. Linear sequences may help to bypass these unwanted interactions. However, in spite of the high immune response and recognition of native toxin $B$ by some anti-MAPs, none of the antibodies neutralised cytotoxicity. Even if they do not induce protective antibodies, peptide antigens might be used to prime the host before boosting with low doses of native toxins, which would normally be non-immunogenic, as has been shown with some viral antigens [34]. 


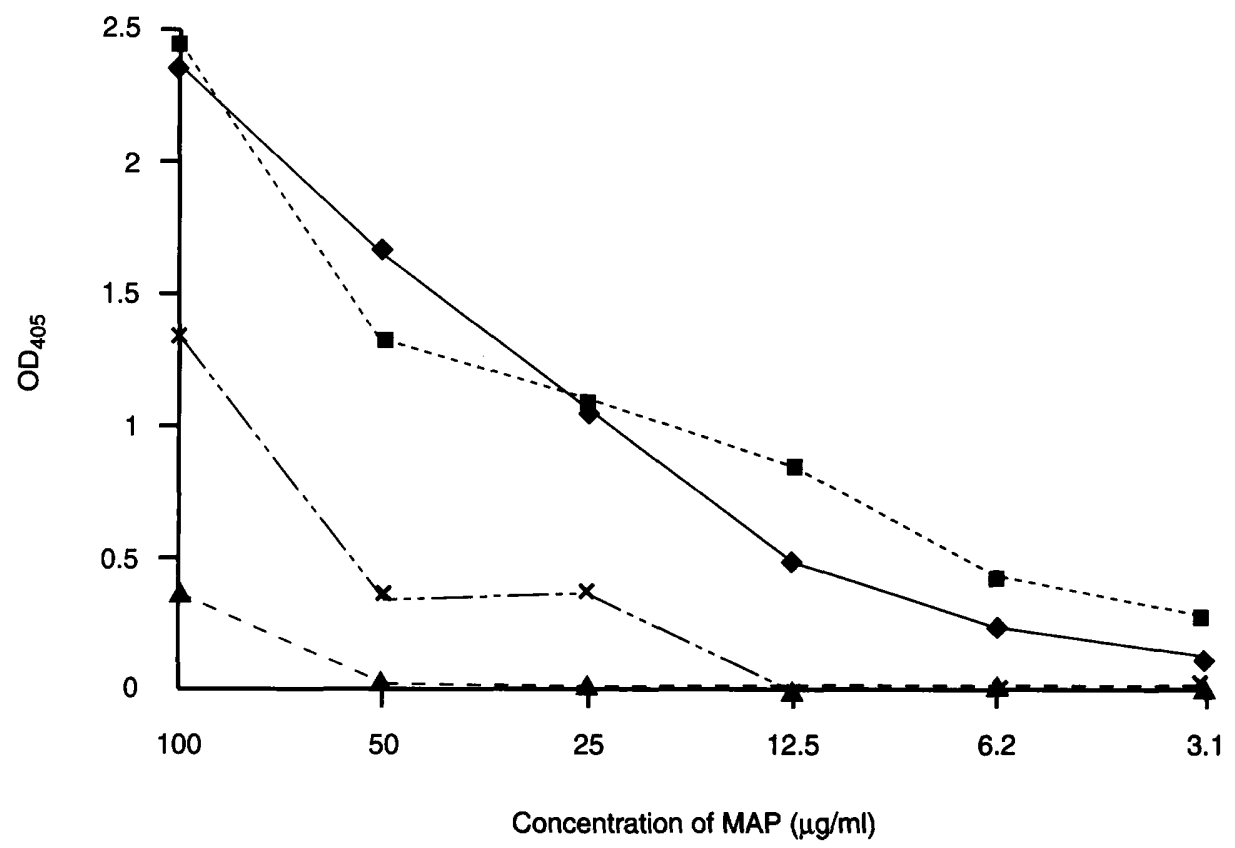

Fig. 8. Binding of tetraMAPs $4\left(-\boldsymbol{\Delta}_{-}\right), 7(-\times \times \cdot-), 11(--)$ and $12(-----)$, to native toxin B in ELISA with different concentrations of the MAPs and microtitration plates coated with toxin B. The absorbance obtained in a direct reaction between anti-MAP and toxin B was subtracted from the absorbance obtained when toxin B was first mixed with the respective tetraMAP.

When the reaction of anti-MAPs with toxin $B$ was studied by immunoblotting, polymers of the toxin were hardly recognised, whereas peptides with sizes down to $c$. $40 \mathrm{kDa}$ were recognised by some antiMAPs, supporting previous suggestions that toxin B is frequently hydrolysed into smaller peptides during purification. Anti-MAPs 3,6 and 7 recognised native toxin $\mathrm{A}$ in ELISA and denatured toxin in SDS-PAGE; in clear contrast with the reaction with toxin $B$, these antisera recognised toxin A polymers or aggregates, suggesting that these epitopes are presented as conformational epitopes when toxin $\mathrm{A}$ is not denatured. It might also be possible that the reported nonspecific interaction of mouse IgG with toxin $A$ is favoured when this toxin is polymerised [35].

Anti-MAP 11 recognises native toxin $\mathrm{A}$ but not native toxin $\mathrm{B}$; on the contrary, it recognised denatured toxin $\mathrm{B}$ but not denatured toxin $\mathrm{A}$. We have no clear explanation for this finding; it is possible that, as suggested above, whereas the recognised epitope is linear in toxin $\mathrm{B}$, it is conformational in toxin $\mathrm{A}$.

In toxin $\mathrm{A}$, the $\mathrm{C}$-terminal repetitive sequences are highly immunogenic and studies with recombinant peptides and monoclonal antibodies suggest that conformational epitopes and not linear sequences are able to induce protective antibodies [25]. The present study also shows that linear sequences of the repetitive domains in the $\mathrm{C}$-terminal region of toxin $\mathrm{B}$ do not induce anti-cytotoxic antibodies. The C-terminal region is highly homologous between the toxins [24], explaining the cross-reactions observed with some of the anti-MAPs. The C-terminal repeats of both toxins have partial homology to the $\mathrm{C}$-terminal repeats observed in streptococcal glucosyltransferases [36]. In toxin $A$ and in streptococcal glucosyltransferase, this region is responsible for binding the protein to specific oligosaccharides; by analogy, toxin B repeats are suspected to bind the toxin to its receptor. The receptor for toxin B is unknown, but antibodies preventing its binding should show protection. Although none of the anti-MAPs neutralised the cytotoxicity of toxin B, four peptides (MAPs 4, 7, 11 and 12) inhibited cytotoxicity. This inhibition seems to be due to a direct interaction of the MAP with the toxin, because: (1) antibodies to the MAP did not inhibit cytotoxicity; (2) the inhibition was evident only when MAP was added to the cells together with the toxin or shortly after it; and (3) the MAP reacted directly with the toxin as tested in ELISA. However, direct interaction with toxin B may not be the only cause since differences in binding ability, as measured by ELISA, do not correlate with the magnitude of inhibition of cytotoxicity. The relevance of the cytotoxic activity of toxin B in intestinal disease is unknown, and, at this time, it is difficult to say whether this MAP would have therapeutic potential.

\section{References}

1. Lyerly DM, Saum KE, MacDonald DK, Wilkins TD. Effects of Clostridium difficile toxins given intragastrically to animals. Infect Immun 1985; 47: 349-352.

2. Mitchell TJ, Ketley JM, Haslam SC et al. Effect of toxin A and B of Clostridium difficile on rabbit ileum and colon. Gut 1986; 27: 78-85.

3. Torres J, Jennische E, Lange S, Lönnroth I. Enterotoxins from Clostridium difficile; diarrhoeogenic potency and morphological effects in the rat intestine. Gut 1990; 31: 781-785. 
4. Hecht G, Pothoulakis C, LaMont JT, Madara JL. Clostridium difficile toxin A perturbs cytoskeletal structure and tight junction permeability of cultured human intestinal epithelial monolayers. J Clin Invest 1988; 82: 1516-1524.

5. Flegel WA, Müller F, Däubener W, Fischer H-G, Hadding U, Northoff $\mathrm{H}$. Cytokines response by human monocytes to Clostridium difficile toxin A and toxin B. Infect Immun 1991; 59: 3659-3666.

6. Miller PD, Pothoulakis C, Baeker TR, LaMont JT, Rothstein TL. Macrophage-dependent stimulation of $T$ cell-depleted spleen cells by Clostridium difficile toxin $\mathrm{A}$ and calcium ionophore. Cell Immunol 1990; 126: 155-163.

7. Malorni W, Paradisi S, Dupuis ML, Fiorentini C, Ramoni C. Enhancement of cell-mediated cytotoxicity by Clostridium difficile toxin A: an in vitro study. Toxicon 1991; 29: 417-428.

8. Pothoulakis C, Sullivan R, Melnick DA et al. Clostridium difficile toxin A stimulates intracellular calcium release and chemotactic response in human granulocytes. $J$ Clin Invest 1988; 81: 1741-1745.

9. Pothoulakis C, Karmeli F, Kelly CP et al. Ketotifen inhibits Clostridium difficile toxin A-induced enteritis in rat ileum. Gastroenterology 1993; 105: 701-707.

10. Hecht G, Koutsouris A, Pothoulakis C, LaMont JT, Madara JL. Clostridium difficile toxin $\mathrm{B}$ disrupts the barrier function of $\mathrm{T}_{84}$ monolayers. Gastroenterology 1992; 102: 416-423.

11. Siffert JC, Baldacini O, Kuhry JG et al. Effects of Clostridium difficile toxin $\mathrm{B}$ on human monocytes and macrophages: possible relationship with cytoskeletal rearrangement. Infect Immun 1993; 61: 1082-1090.

12. Kelly CP, Pothoulakis C, LaMont JT. Clostridium difficile colitis. $N$ Engl J Med 1994; 330: 257-262.

13. Viscidi $R$, Laughon BE, Yolken $\mathrm{R}$ et al. Serum antibody response to toxins $\mathrm{A}$ and $\mathrm{B}$ of Clostridium difficile. $J$ Infect Dis 1983; 148: 93-100.

14. Leung DYM, Kelly CP, Boguniewicz M, Pothoulakis C, LaMont JT, Flores A. Treatment with intravenously administered gamma globulin of chronic relapsing colitis induced by Clostridium difficile toxin. $J$ Pediatr 1991; 118: 633-637.

15. Warny M, Vaerman J-P, Avesani V, Delmée M. Human antibody response to Clostridium difficile toxin $\mathrm{A}$ in relation to clinical course of infection. Infect Immun 1994; 62: 384 389.

16. Johnson S, Gerding DN, Janoff EN. Systemic and mucosal antibody responses to toxin $A$ in patients infected with Clostridium difficile. J Infect Dis 1992; 166: 1287-1294.

17. Fernie DS, Thomson RO, Batty I, Walker PD. Active and passive immunization to protect against antibiotic associated caecitis in hamsters. Dev Biol Stand 1983; 53: 325-332.

18. Kim P-H, Iaconis JP, Rolfe RD. Immunization of adult hamsters against Clostridium difficile-associated ileocecitis and transfer of protection to infant hamsters. Infect Immun 1987; 55: 2984-2992.

19. Libby JM, Jortner BS, Wilkins TD. Effects of the two toxins of Clostridium difficile in antibiotic-associated cecitis in hamsters. Infect Immun 1982; 36: 822-829.

20. Ketley JM, Mitchell TJ, Candy DCA, Burdon DW, Stephen J.
The effects of Clostridium difficile crude toxins and toxin A on ileal and colonic loops in immune and non-immune rabbits. $J$ Med Microbiol 1987; 24: 41-52.

21. Barroso LA, Wang S-Z, Phelps CJ, Johnson JL, Wilkins TD. Nucleotide sequence of Clostridium difficile toxin B gene. Nucleic Acids Res 1990; 18: 4004.

22. Dove $\mathrm{CH}$, Wang S-Z, Price SB et al. Molecular characterization of the Clostridium difficile toxin A gene. Infect Immun 1990; 58: $480-488$.

23. Barroso LA, Moncrief JS, Lyerly DM, Wilkins TD. Mutagenesis of the Clostridium difficile toxin B gene and effect on cytotoxic activity. Microb Pathog 1994; 16: 297-303.

24. von Eichel-Streiber C, Laufenberg-Feldmann R, Sartingen S Schulze J, Sauerborn M. Comparative sequence analysis of the Clostridium difficile toxins A and B. Mol Gen Genet 1992 233: $260-268$

25. Frey SM, Wilkins TD. Localization of two epitopes recognized by monoclonal antibody PCG-4 on Clostridium difficile toxin A. Infect Immun 1992; 60: 2488-2492.

26. Lyerly DM, Phelps CJ, Toth J, Wilkins TD. Characterization of toxins $\mathrm{A}$ and $\mathrm{B}$ of Clostridium difficile with monoclonal antibodies. Infect Immun 1986; 54: 70-76.

27. Tam JP. Synthetic peptide vaccine design: synthesis and properties of a high-density multiple antigen peptide system. Proc Natl Acad Sci USA 1988; 85: 5409-5413.

28. Reynolds SR, Dahl CE, Harn DA. T and B epitope determination and analysis of multiple antigenic peptides for the Schistosoma mansoni experimental vaccine triose-phosphate isomerase. J Immunol 1994; 152: 193-200.

29. Torres JF, Lönnroth I. Production, purification and characterisation of Clostridium difficile toxic proteins different from toxin A and from toxin B. Biochim Biophys Acta 1989; 998: $151-157$.

30. Tam JP, Clavijo P, Lu Y-A, Nussenzweig V, Nussenzweig $R$, Zavala F. Incorporation of $T$ and $B$ epitopes of the circumsporozoite protein in a chemically defined synthetic vaccine against malaria. $J$ Exp Med 1990; 171: 299-306.

31. Coffman RL, Seymour BWP, Lebman DA et al. The role of helper $\mathrm{T}$ cell products in mouse $\mathrm{B}$ cell differentiation and isotype regulation. Immunol Rev 1988; 102: 5-28.

32. Mosmann TR, Coffman RL. Th1 and Th2 cells: different patterns of lymphokine secretion lead to different functional properties. Annu Rev Immunol 1989; 7: 145-173.

33. Däubener $W$, Leiser $E$, von Eichel-Streiber $C$, Hadding $U$ Clostridium difficile toxins $\mathrm{A}$ and $\mathrm{B}$ inhibit human immune response in vitro. Infect Immun 1988; 56: 1107-1112.

34. Emini EA, Jameson BA, Wimmer E. Priming for and induction of anti-poliovirus neutralizing antibodies by synthetic peptides. Nature 1983; 304: 699-703.

35. Lyerly DM, Carrig PE, Wilkins TD. Nonspecific binding of mouse monoclonal antibodies to Clostridium difficile toxins A and B. Curr Microbiol 1989; 19: 303-306.

36. von Eichel-Streiber C, Sauerborn M. Clostridium difficile toxin A carries a $\mathrm{C}$-terminal repetitive structure homologous to the carbohydrate binding region of streptococcal glycosyltransferases. Gene 1990; 96: 107-113. 